\title{
EDUCAÇÃo FíSICA ESCOLAR PELO VIÉS SEMIÓTICO
}

\author{
SCHOOL PHYSICAL EDUCATION THROUGH SEMIOTIC BIAS
}

\author{
Priscila Fátima da Silva Fiel \\ Mestranda em Gestão e Práticas Educacionais \\ Universidade Nove de Julho - UNINOVE. \\ São Paulo, SP - Brasil. \\ priscila.fiel@hotmail.com
}

\author{
Márcia do Carmo Felismino Fusaro \\ Doutora em Comunicação e Semiótica \\ Pontifícia Universidade Católica de São Paulo - PUC-SP. \\ São Paulo, SP - Brasil. \\ profmarciafusaro@gmail.com
}

Resumo: A Semiótica, ciência de estudo dos signos, inaugurada no século XIX por C. S. Peirce, pode ser aplicada a inúmeros contextos, incluindo o da educação. A Educação Física Escolar (EFE), disciplina obrigatória por lei no ensino básico, revela toda uma relação intrínseca aos signos do corpo e da imagem. A essência deste artigo é propor, pelo viés da Semiótica, um diálogo com a Educação Física Escolar, entendendo-se que esta disciplina lida com a prática corporal na construção de significados que se viabilizam por meio do corpo em movimento. Diante deste cenário, propõe-se maiores reflexões sobre o fato de que entender a interação entre alunos e professores como formadora de signos, na dinâmica das aulas, pode proporcionar um maior aprofundamento nas pesquisas educacionais sobre os signos relacionados ao corpo e à imagem na Educação Física Escolar.

Palavras-chave: educação física escolar; semiótica; corpo; imagem.

Abstract: Semiotics, the science of study of signs, inaugurated in the 19th century by C. S. Peirce, can be applied to countless contexts, including that of education. Physics Education (PE), mandatory subject by law in basic education, reveals an intrinsic relationship to the signs of the body and image. The essence of this article is to propose, through Semiotics, a dialogue with Physics Education, understanding that this discipline deals with the corporal practice in the construction of meanings that are made possible through the body in movement. In view of this scenario, further reflections are proposed on the fact that understanding the interaction between students and teachers as a sign maker, in the dynamics of classes, can provide greater depth in educational research on signs related to the body and image in Physics Education.

Keywords: physics education; semiotics; body; image.

\section{Para citar - ABNT NBR 6023:2018}

FIEL, Priscila Fátima da Silva; FUSARO, Márcia do Carmo Felismino. Educação física escolar pelo viés semiótico. Cadernos de Pós-graduação, São Paulo, v. 20, n. 1, p. 232-241, jan./jun. 2021. Disponível em: https://doi.org/10.5585/cpg.v20n1.19504. 


\section{Introdução}

A Semiótica é a ciência de estudo dos signos. Inaugurada no século XIX, por Charles Sanders Pierce (SANTAELLA, 1983), tem como desafio estudar as infinitas possibilidades de intersemiose, ou seja, as relações entre os signos em nossa leitura de mundo. A Educação Física Escolar (EFE), disciplina obrigatória na educação escolar, tem como competência o estudo das linguagens e a compreensão do corpo em suas diversas funções, sobretudo motoras. Neste artigo, proporemos uma aplicação da Semiótica como fundamento para o estudo da produção de signos relacionados ao corpo e à imagem na Educação Física, com o objetivo de entender e analisar melhor as produções de linguagens da Educação Física na área da Educação, sem, no entanto, a pretensão de esgotar um tema tão vasto.

Com o passar dos anos, principalmente ao longo do século XX, houve mudanças na ótica corporal, avançando da condição somente biológica para uma exploração de condição mais social e cultural, proporcionando um olhar diferente sobre a Educação Física. Os códigos que existem na disciplina têm como função limitar atitudes de escolha e interpretação, delimitando a validação ou não dos signos. Dentro dessa perspectiva começou a existir troca de informações entre professor e aluno, resultando em melhor alcance da realidade, adaptação, comunicação e socialização nas aulas de Educação Física Escolar.

O processo cultural foi encarado com profundidade nesse processo, acessando esse corpo em sua ação por meio da linguagem. O corpo é signo de interlocução entre o mundo, os sujeitos e as relações pessoais, ou seja, o corpo está em contato com símbolos, interpretações, identidades, culturas, entre outras características compartilhadas em sociedade.

\section{A Educação Física Escolar (EFE) e sua importância na educação}

De acordo com Betti et al (2007) em 01/11/1971, a EFE passou pelo decreto nº 69.450 e se iniciou nos currículos escolares de todas as séries de qualquer sistema de ensino como atividade regular e obrigatória (BRASIL, 1971).

Para Costa e Silva (2016), no fim do século XIX, as características das aulas de EFE apresentavam como proposta o viés higienista que se encaminhou, posteriormente, para uma intenção militar, seguindo pelo caminho esportivista. Atualmente, a EFE propõe, por meio de sua prática, reflexões do aluno e do professor sobre cultura, expressão corporal, conhecimento de mundo, diálogos sobre temas pertinentes e necessários para a formação do ser humano, por meio de jogos, brincadeiras, circo, esporte, lutas, capoeira, ginástica, entre outros. 
Paiva e Betti (2007) afirmam que depois de 1980 houve mudanças nas abordagens, passando por uma pedagogia de cunho humanista. Alguns autores considerados clássicos e que fizeram parte, de alguma forma, dessa trajetória são: Tani (1987), Freire (1989), Betti (1991, 1992), Kunz $(1991,2006)$, Bracht (1999), dentre outros que colaboraram para a EFE sair do campo somente biológico e adentrar também no diálogo com as áreas das ciências humanas e filosóficas.

Segundo Daólio (1996), a EFE tem como meta partir de um ponto já conhecido da cultura popular do movimento para variações de expressão e significados que proporcionem ao aluno um aprendizado emancipatório e crítico sobre a cultura corporal. Este deveria ser um dos objetivos da disciplina, porém ainda não se vê clareza e contextualização de forma abundante a respeito disso. A área acadêmica em EFE vem se ampliando significativamente, no entanto, ainda se vê longe de uma prática pedagógica bem-pensante dentro da quadra.

Ainda conforme Daólio (1996), no teor da prática cultural, a EFE possui valores que diferem conforme o público e o cenário. Tratam-se de características identitárias, pois, de certo modo, existe um "jeito particularizado" de ministrar as aulas. Por isso, quando pensamos sobre as necessidades de transformação da EFE, entendemos também não se tratar de algo rápido e muito menos fácil.

Infelizmente, ela [a EFE] não depende diretamente apenas de uma melhoria na formação profissional, ou de um significativo aumento salarial para os professores, ou somente de uma maior dotação de materiais para as aulas. Embora esses fatores sejam necessários, eles parecem não ser suficientes para a revisão do papel da Educação Física Escolar, já que esbarram na própria tradição cultural da prática (DAÓLIO, 1996, p. 01).

Tahara e Darido (2016), por sua vez, dizem que a Educação Física Escolar (EFE) traz aos estudantes uma variedade de conteúdos pertinentes sobre a cultura corporal do movimento, assunto este que aborda o conhecimento do e sobre o corpo. O professor, no papel de mediador, sistematiza esses conteúdos de forma que se tornem eficientes para a aprendizagem do aluno. Apesar de se tratar de um campo de pesquisa que ainda requer maiores reflexões e reconhecimento, é possível notar que a disciplina EFE vem ganhando notoriedade ao longo dos anos, estabelecendo graus de importância, identidade e legitimidade dentro das escolas.

\section{Breves noções sobre signo pela perspectiva da semiótica peirceana}

Segundo Santaella (1983), a palavra "semiótica” vem d raiz grega semeion, que significa signo. Trata-se, portanto, da ciência dos signos, da linguagem. A Semiótica de Charles Sanders Peirce tem como base a formação da tríade de categorias universais do pensamento e da natureza, nomeadas de primeiridade, secundidade e terceiridade. Essas categorias são cabíveis a qualquer linha de pensamento, já que se entende o pensamento também como signo. Além disso, a Semiótica peirceana nasce, primeiramente, como lógica e não como ciência aplicada. Conforme Santaella (1983, p. 11), 
"Peirce conseguiu que seus conceitos sobre semiótica atingissem qualquer ciência, e não somente alguma área específica".

Santaella (1983, p. 43-54) prossegue, ainda, com a definição de Primeiridade, que na linguagem peirceana é a primeira qualidade que vem à mente de alguém no presente imediato, é a sensação instantânea, primeiríssima. A Primeiridade, no entanto, é apenas parte do fenômeno, pois para que ela exista é preciso a Secundidade, ou seja, o momento posterior em que a matéria encarna aquela sensação primeira presente na Primeiridade. O existir se faz nessa corporificação material que é a Secundidade. A Terceiridade aproxima a primeira e a segunda categorias em uma síntese intelectual, portanto ligada ao pensamento, por meio da qual lemos o mundo por meio da interação entre os signos presentes em todo esse processo. "Para conhecer e compreender qualquer coisa, a consciência produz um signo, ou seja, um pensamento como mediação entre nós e os fenômenos" (SANTAELLA, 1983, p. 51).

Peirce define o signo em uma tríade de aprofundamento diretamente associada aos itens anteriores, a saber: ícone (primeiridade), índice (secundidade) e símbolo (terceiridade). Iniciando pelo ícone, em sua subjetividade ele pode ser o próprio objeto, pois, nesse caso, signo e objeto se harmonizam entre si. Isso acontece pelo fato de o ícone representar signos de acesso imediato. Exemplo disso é a criança na mais tenra idade acessando o mundo. Ela é puro sentir! Puro experimentar sem que se estabeleçam ainda conexões entre os seres e os fenômenos e os nomes a estes associados. O índice, por sua vez, é justamente o signo de associação entre os seres e os fenômenos e seus reconhecimentos como tal no mundo que nos cerca, aproximando-se do objeto pelo viés de existência e mostrando uma relação direta com este objeto para existir. Um exemplo para ilustração é a nuvem que se transforma em chuva e possibilita a existência de "pegadas", ou seja, o índice (indício) de que algo ou alguém passou por ali. Símbolo, por sua vez, associado à terceiridade, é um signo que existe através de uma síntese intelectual. É o pensamento (signo) que para (se) pensar, necessita gerar outros signos, assim se estendendo incessantemente. Tem-se exemplo disso no dicionário: o significado de um pensamento (signo) é outro pensamento (signo). Para explicar o significado de uma palavra, recorre-se a outra palavra que, de modo sintético, explique e substitua o sentido anterior. Essas três categorias, no entanto, devem ser interpretadas sempre em relações dinâmicas de interação. Elas não existem de forma separada. Uma depende dinamicamente da outra para se manifestar. Em suma, a teoria de Peirce vai além do sentido escrito de uma teoria, constituindo-se em uma lógica.

Especificamente em relação à imagem, e de acordo com Santaella (2010), o produto imagem (linguagem não verbal) se divide em duas vertentes: a imagem visual, que pode ser represen- 
tada por quadros, desenhos, filmes, revistas e que possuem significados no ambiente em que vivemos; a segunda vertente é a imagem de domínio imaterial: fantasias, representações mentais. É importante considerarmos esses conceitos relacionados à imagem, considerada em sua manifestação subjetiva e mental, como fundamentação ao que pode servir de ponte para algumas reflexões sobre o papel da imagem (entendida como signo) relacionada ao trabalho educacional com o corpo na Educação Física Escolar.

\section{O corpo na perspectiva da Educação Física Escolar (EFE)}

De acordo com Baldissera (2008), o mundo se torna o que é por meio do tipo de imagem mostrada e ressignificada pelo ser humano. Essa imagem caminha por dois vieses: a existência por si só e o modelo no qual existe, ou seja, o significado que tal imagem apresenta segundo nossa interpretação.

A imagem corporal é perpassada pelo viés fisiológico e se transforma de acordo com o ambiente onde está inserida. Esse ambiente pode variar de acordo com a localidade, o tempo, a memória, o modismo, entre outros fatores. Segundo Tahara e Darido (2016), a EFE se apropriou da cultura corporal produzida pela sociedade em seus diversos segmentos: circo, esportes, lutas, dança, ginástica. Tais segmentos têm como valor a representação da imagem corporal, que possui atributos voltados à qualidade de vida, bem-estar, condicionamento, estética. Todavia, embora esses conteúdos sejam de extrema importância, se não forem ressignificados pelo professor e contextualizados aos alunos, acabarão por se perder no cotidiano da escola.

Segundo Farias (1999), Peirce aponta um caminho para a formação de uma nova visão de mundo, apresentando o pensamento como um sistema maior do que o próprio indivíduo. Isso porque, por essa linha, o pensamento não está em nós, nós é que estamos no pensamento. Seria como se tivéssemos acesso a um campo de informações que se manifesta significativamente por meio do hábito, que, por sua vez, trata-se de um padrão que nos configura. Logo, a lei do hábito se sobrepõe ao indivíduo, ou seja, ao próprio ser humano. O sistema filosófico de Peirce visa abranger a amplitude da objetividade do mundo e do próprio sujeito, a partir do que foi explanado.

Costa e Silva (2016) dizem que, com o passar do tempo, o homem quer apresentar seu corpo cada vez melhor. A aparência se tornou identidade do ser humano. Segundo Abreu et al (2019), em nossa sociedade o corpo se converteu em tendência articulada de acordo com o momento em que se vive. A transformação do corpo passou a ser vista como algo comum e necessário.

Segundo Santaella (2004), o corpo pode ser considerado também como arte. Figura em movimento, flexível, que possui um "motor" interno, motor este emanador de sinais, magia, leituras, interpretações. Ainda conforme a pesquisadora, as imagens são representações criadas pelo ser 
humano de acordo com o momento em que vive, e a representação vai se transformando através do tempo. Assim é que, a nosso ver, corpo, arte, imagem e movimento podem integrar uma perspectiva semiótica com vistas enriquecedoras à educação. Trataremos um pouco mais sobre isso no próximo segmento.

$\mathrm{Na}$ área educacional, onde acontecem problematizações sobre assuntos pertinentes, trazidos muitas vezes pelos próprios alunos, por que não falar mais sobre o corpo? O corpo físico e social se mostra como assunto muito atual e importante a ser desenvolvido no cotidiano das aulas. Afinal, o corpo está presente em todos os lugares, em diferentes formas e culturas. Nesse contexto, a EFE, por si só, já se apresenta como conteúdo propício à abordagem que diz respeito ao corpo. Padrões corpóreos, bulimia, anorexia, bullying, obesidade são alguns dos inúmeros temas participantes da realidade dos alunos e que podem ser tratados por uma perspectiva mais semiótica, a considerar aspectos verbais e não verbais nessa abordagem. Nesse contexto, a atuação inteligente do professor, como mediador, pode suscitar novas e criativas reflexões a respeito do corpo, a fim de desconstruir indesejáveis paradigmas oriundos do ambiente escolar.

Assim é que Gaya (2006) nos alerta sobre o corpo na escola permanecer adormecido, esquecido, deixado de lado. Mas, afinal, não somos nosso corpo? Entendido por esse caminho reflexivo, vê-se quanto o corpo e as prioridades pedagógicas na escola ainda necessitam de uma via de maior diálogo e fundamentação conceitual. Isso porque, ainda que esteja presente na escola, é como se o corpo permanecesse ausente. A forma como que ele é abordado no âmbito pedagógico segue em um movimento ainda superficial, deixando de lado a possibilidade de se progredir para uma pedagogia integradora. De fato, todas as disciplinas deveriam reivindicar leituras mais profundas sobre a importância do corpo na escola, e não somente a Educação Física.

Ainda conforme Gaya (2006), o corpo valioso é aquele que se movimenta, seja para cozinhar, dançar, fazer esportes, corpo que fica doente, obeso, esbelto, rápido, forte ou fraco, feliz, triste, ansioso, todos esses exemplos de corpo deveriam ter lugar mais presente na vida real considerada na educação. Somos corpo, tanto quanto mente. A EFE reconhece e acolhe o corpo, porém, para uma educação integrada, envolvendo desde a gestão até os professores de outras disciplinas, é necessário enxergar o aluno também como corpo e mente. Indivíduo que pensa e age.

De acordo com Bracht (2005), existem contextos escolares em que o trabalho com o corpo é usado como moeda de troca. É quando ainda se ouvem frases do tipo: "Se não fizer a atividade de matemática, não brinca!". Na escola, onde o processo de ensino e aprendizagem é algo inerente, é necessário considerar o corpo a partir de perspectivas também mais subjetivas: o corpo submetido ao esquecimento, à lembrança, à vontade, à preguiça, entre inúmeros outros aspectos. Lembre-se, 
ainda, que o acesso ao sensório também se inicia pelo corpo: visão, fala, audição, tato, olfato, paladar... Em suma, não existe aprendizagem sem o corpo, e este é um aspecto altamente relevante que não deve ser ignorado na educação.

\section{Educação Física e Semiótica: preâmbulos}

Betti (2007) afirma que quando recorremos à Semiótica, teoria geral dos signos desenvolvida por Charles Sanders Peirce, deparamo-nos com uma reflexão profunda sobre o que o signo propõe. O ser humano se expressa e acessa o mundo, fundamentalmente, por meio de signos. Nesse sentido é que também são signos, por exemplo, os gestos e movimentos corporais que acompanham a fala e a audição no momento da comunicação.

Todavia, não somente Betti (2007), como vários outros estudiosos entendem que a Semiótica não é somente um fenômeno corpóreo, mas uma lógica voltada ao estudo do signo que nos possibilita uma leitura mais sofisticada de mundo, por considerar os aspectos da linguagem não verbal, tanto quanto a verbal, em nossa interação com o mundo. Partindo desse pressuposto, tornase viável pensar o cotidiano das aulas de EFE também como ambiente onde pode ser possível uma sofisticação de leitura que considere o corpo e seus atributos como signos em movimento. Mas para que uma tal leitura seja bem-sucedida, faz-se fundamental o engajamento entre professor e aluno na construção de uma prática pedagógica voltada à apreciação de valores colaborativos e culturais de base semiótica. De um ponto de vista semiótico, na EFE é possível ler índices sígnicos até mesmo, apenas para citar apenas um exemplo, no suor expelido pelo corpo e tudo que diz respeito a isso no contexto não somente mais estrito da aula, mas também para além da sala de aula. Entenda-se, ainda, que a EFE, evidentemente, não se restringe apenas à cultura corporal, nem somente à fisiologia do exercício.

\footnotetext{
Devemos pensá-la como o conjunto dos processos orgânicos/filogenéticos e sócio-históricos, presentes no movimentar-se mais espontâneo da vida cotidiana ou em movimentos corporais organizados em sistemas gestuais, como práticas sistemáticas e intencionadas, das ações circenses aos treinamentos resistidos ou funcionais (BETTI et al, 2013, p. 93).
}

Diversos fatores como confiança, empatia, motivação, corroboram com o processo de ensino-aprendizagem, juntamente com o método de ensinar que também modifica essa ação (Betti et al, 2013). A brincadeira ou o esporte, o jogo, do passe à dança, do golpe ao arremesso, constitui-se em ato de semiose (produção de significados por meio de signos) gerador de comunicação e novos significados. A semiose gerada durante as práticas corporais da EFE estabelece ponte entre quem participa e quem assiste, criando contextos geradores de novas possibilidades educacionais relacionadas ao corpo entendido como signo. 
Segundo Cocchieri (2018), por trás da Semiótica existe uma visão de cultura definida como padrão criador de significados, levando em consideração que o homem é um produtor cultural, e que essa cultura pode ser entendida como um processo de símbolos que se modifica com o passar do tempo. Dessa forma, a Semiótica avança e os signos vão criando sua própria identidade em novas significações. Nesse processo, é possível, inclusive, surgirem indagações de onde vêm os momentos anteriores de interação das significações, a produção de significado.

Betti (2013) afirma que todo código possui uma linguagem, porém nem toda linguagem é um código. A linguagem é um caminho e o código é o resultado. Muitas vezes as interações entre signos são estagnadas em certo momento cultural para ser entendido como um "código" que possibilita limitações interpretativas. O mesmo autor também argumenta que o signo é uma escolha dentre outras tantas escolhas interpretativas, não só para o que é valido, aceito, mas também para o que não é. O signo é composto por regras, seguido de previsibilidades, comportamentos passíveis a serem condicionados.

Um exemplo citado pelo mesmo autor acima mencionado é a ginástica artística, que tem como acordo signos atuantes em seus movimentos, posturas, gestos, sendo que qualquer signo que se diferencia do esperado (um movimento inédito, por exemplo) só tem seu valor reconhecido se estiver dentro dos padrões já estabelecidos, ou seja, dos códigos já institucionalizados.

Vê-se, dessa forma, algumas breves contextualizações sobre possíveis interfaces entre a EFE e a Semiótica como base para um ensino-aprendizagem mais aprofundados a partir do corpo entendido como signo em movimento.

\section{Considerações Finais}

O corpo desperta efeitos culturais, e é também influenciado por eles, na EFE. Os alunos, às vezes, imitam movimentos referentes a um modelo específico nas aulas, aqueles de um atleta, por exemplo, e estes, por sua vez, causam certos efeitos nas aulas, pois o professor atento à realidade escolar vai entender esse signo e, de alguma forma, assimilá-lo em sua prática pedagógica. Esse novo movimento, por sua vez, pode modificar toda uma relação de movimento-signo-cultura dentro e fora da escola.

A significação e a ressignificação da imagem-corpo vão surgindo à medida que os contextos, especialmente os educacionais, vão se transformando. As regras dos esportes, como tantas outras características, modificam-se com o passar do tempo, gerando novas oportunidades de entendimento sobre o corpo e a prática da educação física. Conforme apontamos, a Educação Física Escolar permite, em suas aulas, relações e leituras semióticas entre professores e alunos, participantes da significação dos corpos, seja pelo olhar fisiológico ou cultural, biológico ou social. Nessa 
perspectiva, a Semiótica aplicada à Educação Física Escolar pode não somente propor momentos cognitivos necessários ao entendimento mais sofisticado sobre a dinâmica do corpo e a consciência corporal, mas também produzir novos conhecimentos sobre si mesmos e o mundo aos atores envolvidos no contexto educacional.

\section{Referências}

ABREU. Samara Moura Barreto de; SABÓIA, Wilson Nóbrega; NOBREGA-THERRIEN. Silvia Maria. Formação docente em educação física: perspectivas de uma racionalidade pedagógica do corpo em movimento. Educaşão \& Formação, v. 4, n. 12set/dez, 2019, p. 191-206.

BALDISSERA, Rudimar. Significação e comunicação na construção da imagem-conceito. Fronteiras-estudos midiáticos, v. 10, n. 3, 2008, p. 193-200.

BETTI, Mauro; SILVA, Eliane Gomes da; SILVA, Pierre Normando Gomes da. Uma gota de suor e o universo da educação física: um olhar semiótico para as práticas corporais. Revista Kinesis, v. 31, n.1, jan/jul 2013, p. 91-106.

BETTI, Mauro et al. Por uma didática da possibilidade: implicações da fenomenologia de Merleau-Ponty para a educação física. Revista brasileira de ciências do esporte, v. 28, n. 2, 2007, p. 39-53.

BETTI, Mauro. Educação física e cultura corporal de movimento: uma perspectiva fenomenológica e semiótica. Journal of Physical Education, 2007, n.18.2, p. 207-217.

BRACHT, V. Cultura corporal, cultura de movimento ou cultura corporal de movimento? In: SOUZA JÚNIOR, M. Educação Física Escolar: teoria e política curricular, saberes escolares e proposta pedagógica. Recife: EDUPE, 2005. p. 97-106.

COCCHIERI, Tiziana et al. O signo e a experiência: a lógica semiótica de Charles Sanders Peirce. Tese de doutorado. Rio Grande do Sul: PUCRS, 2018.

COSTA, Naiana Thaíssa Menezes; SILVA, Alan Camargo. Corpo e educação física escolar no ensino médio: a visão dos alunos. Revista Brasileira de Ciências do Esporte, v. 36, 2016.

DAÓLIO, Jocimar. Educação física escolar: em busca da pluralidade. Revista Paulista de Educação Física, 1996, p. 40-42.

FARIAS. Priscila L. Semiótica e Cognição: os conceitos de hábito e mudança de hábito em C.S. Peirce. Revista eletrônica informação e cognição, v. 1, n. 1, 1999, p. 12-16.

GAYA. Adroaldo. A reinvenção dos corpos: por uma pedagogia da complexidade. Sociologias, n. 15, 2006, p. 250-272.

PAIVA, Bruna Eliza; BETTI, Mauro. O "se-movimentar" como uma experiência do viver: um olhar a partir da semiótica peirceana. In: III CONPEF-Congresso Norte Paranaense de Educação Física Escolar, 2007, p. 1-14.

SANTAELLA, Lucia; NÖTH, Winfried. Imagem: cognição, semiótica, mídia. Sãao Paulo: Iluminuras, 2020. 
SANTAELLA, Lucia. Culturas e artes do pós-humano: da cultura das mídias à cibercultura. São Paulo: Paulus, 2010.

SANTAELLA, Lucia. Corpo e comunicação: sintoma da cultura. São Paulo: Paulus, 2004.

SANTAELLA, Lucia. O que é semiótica. São Paulo: Brasiliense, 1983.

TAHARA, Alexander Klein; DARIDO, Suraya Cristina. Práticas corporais de aventura em aulas de educação física na escola. Conexões, v. 14, n. 2, 2016, p. 113-136. 